\title{
A Clinico-Pathological Study on Dental Treatment for the Handicapped Patient
}

\author{
by \\ Shigeo OTAKE, Toshikazu KUROKI, Rikuo KOSHINO, \\ Naotada SAITO, Yoshikazu KAWABATA, Masayuki ITO* \\ and Susumu UEHARA*
}

(Received 15 October 1985)

\section{Introduction}

A thorough and accurate knowledge of the systemic condition of the patient prior to initiating dental treatment is one of the indispensable requirements for preventing accidents or complications associated with dental procedures and for achieving high-quality dental care. This approach is particularly important for handicapped patients, especially those with internal problems. Such patients usually have some form of communication problem which makes it difficult for the dentist to ascertain any existing systemic problem through routine verbal inquiry. In such cases, in order to evaluate the patient's systemic condition, blood and urine analyses are the most widely used and applicable approaches.

It is this area, the results of blood and urine analyses, which is of great interest to us. Handicapped children may present deviated values in the results of their blood and urine analyses compared with ordinary children due to differences in their living environment, and living pattern including eating habits or food selection. Unexpected findings may also be manifested due to differences associated with anomalies of organic and physiological function that may exist in some handicapped children.

This paper reports the results of a comparative study of blood and urine analysis scores between normal and handicapped persons.

\section{Materials and Methods}

\section{1) Subjects}

The sample subjects were 46 handicapped patients, in the age range of 6 to 22 years, who had visited Nihon University Dental Hospital at Matsudo for dental treatment. The major types of single handicapped conditions among the patients were 16 cases of mental retardation, 10 cases of autism, 5 cases of cerebral palsy with epilepsy, and other miscellaneous conditions as presented in Table 1.

The control group used for comparison was selected from 117 normal persons, who had also visited the Hospital, and who were in the age range of 6 to 19 years. 
Table 1 Types of handicapped children

\begin{tabular}{lc}
\hline Conditions & Number of patients \\
\hline Mental retardation & 16 \\
Autism & 10 \\
Cerebral palsy & 5 \\
Epilepsy & 4 \\
Down's syndrome & 2 \\
Autism +Epilepsy & 2 \\
Cerebral palsy +Epilepsy & 2 \\
Other & 5 \\
\hline
\end{tabular}

Table 2 Selected items for comparison purposes

\begin{tabular}{ll}
\hline RBC & total protein \\
hemoglobin & $\mathrm{A} / \mathrm{G}$ \\
hematocrit & albumin \\
MCH & $\alpha_{1}$-globulin \\
MCV & $\alpha_{2}$-globulin \\
MCHC & $\beta$-globulin \\
& $\gamma$-globulin \\
WBC & fibrinogen \\
stabform leucocyte & glucose \\
segmented leucocyte & total cholesterol \\
eosinophil & Meulengracht \\
basophil & GOT \\
monocyte & GPT \\
lymphocyte & LDH \\
& akaline phosphatase \\
\hline
\end{tabular}

Mean ages of both groups were 13.3 years for the handicapped group and 11.9 years for the normal group.

2) Methods

For comparison of the data between handicapped and normal persons, 34 items were selected from the items employed by the Department of Clinical Laboratory of the Nihon University Dental Hospital at Matsudo in routine evaluation for screening purposes, since these items were applicable for statistical manipulation (Table 2).

Procedures for the analyses were conducted according to the methods routinely employed at our Department and statistical analysis using the t-test was performed after obtaining mean values and S.D. scores.

The height and weight of sample subjects were also measured and the Kaup Index was obtained. For comparison, the standard height and weight figures of the national statistics ${ }^{[1]}$ for each age group were used. Having set the national figure as $100 \%$, the proportionate value of the sample group was obtained as a percentage and presented as $\mathrm{H}^{\%}$, and $\mathrm{W} \%$. As to the Kaup Index, 1.7 which was considered the standard mean score, was considered as $100 \%$ and then the proportionate scores of the sample groups were obtained. 
All statistical calculations were carried out on a personal computer (PC-9801, NEC).

\section{Results}

There were significant differences in 13 items: $\mathrm{RBC}, \mathrm{Hb}$, leukogram (stab.), serum protein, A/G, albumin, $\gamma$-globulin, glucose, total cholesterol, TTT, and ZTT, as shown in Table 3. The handicapped group showed higher scores in all items except for $\mathrm{A} / \mathrm{G}$ and albumin compared with the normal group.

Physical growth of the handicapped group was shown to be $93.0 \pm 10.3 \%$, and the weight as $92.4 \pm 34.8 \%$ for the $\mathrm{H} \%$ indicator. The handicapped group recorded lower scores for both height and weight as compared with normal children. In spite of such retarded growth, the score for the $\mathrm{KI} \%$ indicator showed a higher figure for the handicapped group of $116.8 \pm 29.8 \%$ (Table 4). However, when the histogram of this KI indicator was examined, a normal distribution was not found, and instead, two peaks, at $100 \%$ and $140 \%$, were apparent (Fig. 1).

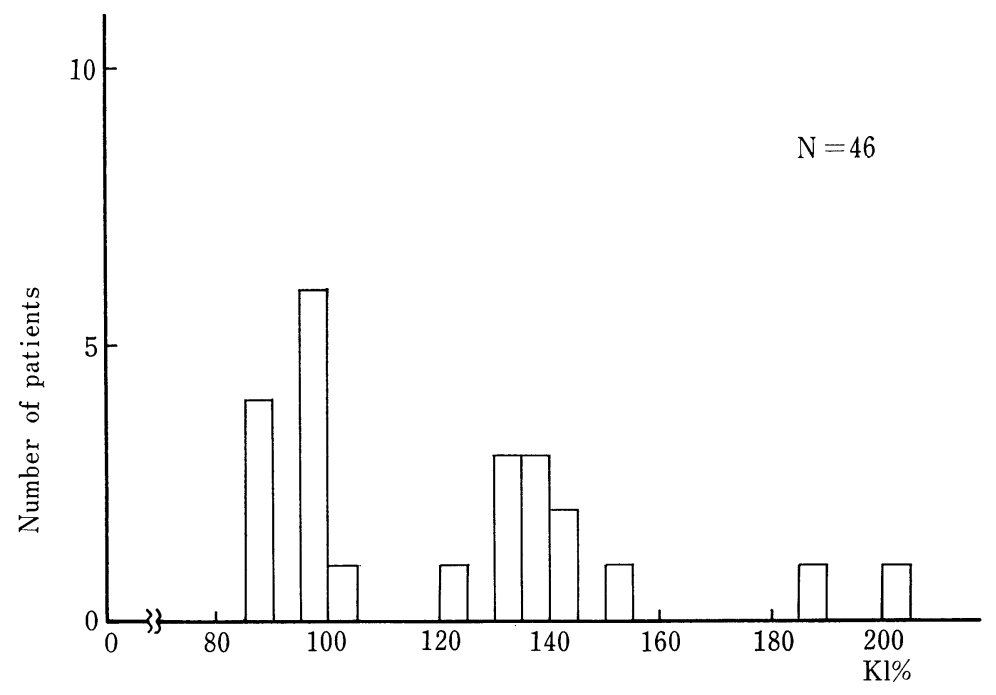

Fig. 1

\section{Discussion and Conclusions}

The handicapped group in this study showed a decreased tendency in the values of $\mathrm{RBC}, \mathrm{Hb}$ and $\mathrm{Ht}$. A similar tendency was quite frequently observed in the case of persons suffering from obesity or hyperalimentation. Unfortunately, insufficiency in the number of samples caused difficulties in carrying out the statistical calculations for triglyceride ${ }^{[2-5]}$, fatty acid ${ }^{[6-7]}$ and total lipid, which reflect the conditions associated with excess weight from the hematological standpoint.

If further samples could be accumulated, the data obtained from the screening test could also be utilized to clarify the nutritional state of such handicapped patients. Higher values of WBC and $\gamma$-globulin and a lower $\mathrm{A} / \mathrm{G}$ value, which are considered 
Table 3 Results of comparison showing significant differences

\begin{tabular}{lccc}
\hline & \multicolumn{3}{c}{ Mean \pm S.D. } \\
\cline { 2 - 4 } & Handicapped & Normal & $\mathrm{t}$-test \\
\hline RBC $\left(\times 10^{4} / \mu \mathrm{l}\right)$ & $488.1 \pm 46.3$ & $466.4 \pm 40.4$ & $\mathrm{p}<0.01$ \\
$\mathrm{Hb}(\mathrm{g} / \mathrm{dl})$ & $14.0 \pm 1.7$ & $13.5 \pm 1.2$ & $\mathrm{p}<0.01$ \\
$\mathrm{Ht}(\%)$ & $42.5 \pm 4.3$ & $41.1 \pm 3.2$ & $\mathrm{p}<0.05$ \\
WBC $(/ \mu \mathrm{l})$ & $7460 \pm 2390$ & $6330 \pm 1900$ & $\mathrm{p}<0.01$ \\
stab. leuco. $(\%)$ & $12.3 \pm 5.3$ & $9.3 \pm 4.8$ & $\mathrm{p}<0.01$ \\
T. protein $(\mathrm{g} / \mathrm{dl})$ & $7.9 \pm 0.6$ & $7.5 \pm 0.5$ & $\mathrm{p}<0.01$ \\
A/G & $1.6 \pm 0.3$ & $1.7 \pm 0.3$ & $\mathrm{p}<0.01$ \\
Albumin $(\%)$ & $61.0 \pm 4.5$ & $63.0 \pm 4.4$ & $\mathrm{p}<0.05$ \\
$\gamma$-globulin $(\%)$ & $16.2 \pm 4.6$ & $14.6 \pm 3.1$ & $\mathrm{p}<0.05$ \\
glucose $(\mathrm{mg} / \mathrm{dl})$ & $91.8 \pm 19.6$ & $85.9 \pm 12.4$ & $\mathrm{p}<0.1$ \\
T. chole. $(\mathrm{mg} / \mathrm{dl})$ & $173.2 \pm 38.2$ & $160.9 \pm 28.6$ & $\mathrm{p}<0.1$ \\
TTT & $3.6 \pm 2.0$ & $2.7 \pm 1.5$ & $\mathrm{p}<0.01$ \\
ZTT & $14.7 \pm 7.2$ & $10.9 \pm 4.3$ & $\mathrm{p}<0.01$ \\
\hline
\end{tabular}

Table 4 Physical growth of handicapped children

\begin{tabular}{lr}
\hline & Mean \pm S.D. \\
\hline $\mathrm{H}^{\circ} \%$ & $93.0 \pm 10.3 \%$ \\
$\mathrm{~W} \%$ & $92.4 \pm 34.8 \%$ \\
$\mathrm{KI} \%$ & $116.8 \pm 29.8 \%$ \\
\hline $\mathrm{H}^{\circ} \%=$ Height $/$ standard height & \\
$\mathrm{W}^{\circ} \%=$ Weight $/$ standard weight & \\
$\mathrm{KI} \%=$ Kaup index $/ 1.7$ &
\end{tabular}

to result from the above condition, and an increased tendency of TTT and ZTT, as compared with normal children, may indicate handicap.

Although the glucose and total cholesterol values failed to show significant differences, the scores in themselves were higher than those of normal children. Since it is generally recognized that glucose and total cholesterol will show a fairly stable value if the sample is obtained when the stomach is empty, a larger standard deviation may indicate the presence of a latent diabetic condition due to the lowering of sugar tolerance ${ }^{[8]}$.

Retarded growth in terms of both height and weight in comparison with normal children using the Kaup Index, and an increased score of $\mathrm{KI}_{\%} \%$ may indicate the presence of obesity in handicapped children. There are some reports ${ }^{[9-10]}$ which have commented on obesity among handicapped children, and generally speaking, this is understandable if we consider their living pattern, particularly their eating habits which include an increased intake of snacks and carbohydrate foods, and the difficulties involved in restricting such behavior.

This fact was revealed by peaks at around $100 \%$ and $140 \%$ when the distribution of $\mathrm{KI} \%$ was examined and in fact one individual had a value of more than $200 \%$. Therefore, the fact that handicapped people are usually obese could have been responsible for this high $\mathrm{KI} \%$ in Fig. 1 .

Further comments are difficult with regard to this study. However, the findings suggest the necessity of further extensive study using an increased sample size and 
a longitudinal study on the same sample subjects in order to clarify their nutritional condition.

The findings of the study also give us the impression that routine blood and urine analyses may have an applicability to the screening of handicapped patients prior to initiating dental procedure in order to evaluate their physio-pathological tolerance while undergoing treatment. Applicability is also indicated for evaluation of nutritional condition, which requires attention as it has some effect on the incidence of caries or susceptibility to dental infection.

\section{References}

[1] Annual Statistical Report on National Health Conditions: Health and Welfare Statistics Association, 1983 (in Japanese)

[2] Albrink, M.J., Meigs, J.W. and Granoff, M.A.: Weight gain and serum triglycerides in normal men, New Eng. J. Med., 266, 484-489, 1962

[3] WAXler, S.H.: and Craig, L.S.: Lipid, cholesterol and triglyceride levels in obese women, Amer. J. Clin. Nut., 14, 128-132, 1964

[4] Nestel, P. and Goldrick, B.: Obesity: Changes in lipid metabolism and the role of insulin, Clin. Endocrinol. Met., 5, 313-335, 1976

[5] Olefsky, J., Reaven, G.M. and Farquhar, J.W.: Effects of weight reduction on obesity, $J$. Clin. Invest., 53, 64-76, 1974

[6] BIRKENHÄGER, J.C. and TJABBES, T.: Turnover rate of plasma FFA and rate of esterification of plasma FFA to plasma triglycerides in obese humans before and after weight reduction, Metabolism, 18, 18-32, 1969

[7] Nestel, P.J. and Whyte, H.M.: Plasma free fatty acid triglyceride turnover in obesity, Metabolism, 17, 1122-1128, 1968

[8] KosaKa, K.: Insulin secretion in diabetes, Internal Medicine, 32, 611-619, 1973 (in Japanese)

[9] Arai, M., Suzumura, M., Hinata, C. and Watanabe, C.: Surveys on food intake of mentally deficient children and college students' attitudes towards them, J. Child. Health, 43, 3138, 1984 (in Japanese)

[10] Guy, R.: The growth of physically handicapped children with emphasis on appetite and activity, Publ. Health, 92, 145-154, 1978 